\title{
Impacts of reducing red meat consumption on agricultural production in Finland
}

\author{
Heikki Lehtonen ${ }^{1}$ and Xavier Irz ${ }^{1}$ \\ ${ }^{1)}$ MTT Agrifood Research Finland/Economic Research, Latokartanonkaari 9 \\ 00790 Helsinki, Finland \\ e-mail: heikki.lehtonen@mtt.fi
}

\begin{abstract}
This paper summarises the simulated effects on Finnish agricultural production and trade of a $20 \%$ decrease in Finnish demand for red meat (beef, pork, lamb). According to our results, reduced red meat consumption would be offset by increased consumption of poultry meat, eggs, dairy products and fish, as well as small increases in consumption of fruits and vegetables, peas, nuts, cereal products and sweets. By including the derived demand changes in an agricultural sector model, we show that livestock production in Finland, incentivised by national production-linked payments for milk and bovine animals, would decrease by much less than $20 \%$ due to the complex nature of agricultural production and trade. Overall, assuming unchanged consumer preferences and agricultural policy, a $20 \%$ reduction in red meat consumption is not likely to lead to a substantial decrease in livestock production or changed land use, or greenhouse gas emissions, from Finnish agriculture.
\end{abstract}

Key words: agricultural sector modelling, food demand, greenhouse gas mitigation, agricultural policy, agricultural economics

\section{Introduction}

It is becoming increasingly clear that what people eat has a significant impact on the environment in general and on greenhouse gas (GHG) emissions in particular (Garnett 2008, Vinnari 2008). For instance, Life Cycle Analysis of foods has repeatedly shown that meat consumption is responsible for relatively more GHG emissions than most other foods and, as a result, a reduction in meat consumption has been advocated as a way of achieving GHG emissions reduction targets (Garnett 2008). Since production of beef and lamb causes significantly higher GHG emissions than pork and poultry meat, reducing consumption of meat from ruminants is considered one of the most effective means for consumers to decrease GHG emissions through their food choices. Further, pork production causes significantly higher GHG emissions than poultry production, and poultry meat includes less saturated fat, potentially harmful to human health, than pork. Consumers have therefore been advised to replace red meat (beef, pork, and lamb) ${ }^{1}$ with poultry meat. Such replacement has been stated as one of the first changes to be implemented, among other such as reducing airline travelling, as a means of reducing GHG emissions through consumption and lifestyle choices. Furthermore, such a change is recommended in recent dietary recommendations which advice replacing saturated fats with non-saturated fats (VRN 2005).

What is remarkable, however, is that meat consumption overall has not been decreasing in Finland - nor in most other European countries since 2000 - despite several years of public debate and discussion about climate impacts of food. Poultry meat consumption has been consistently increasing in Finland since 1995, but beef consumption has remained largely stable while pork consumption has been even increasing in recent years (2009-2010). In addition to this, consumption of cheese and eggs has been increasing as well. Part of this increase could be explained by low-carbohydrate diet (Atkins diet), which advices to replace carbohydrate-rich products such as wheat flourbased and sugar-based food items with foods rich in proteins, easily obtained from livestock products. Hence the consumption of livestock products has even increased since 2000 despite increasing awareness of climate friendly food choices. It seems that reducing red meat consumption has remained as one of the key recommendations for climate friendly diet, but without a considerable effect in the aggregate food consumption. Instead poultry meat and cheese consumption has increased consistently over many years despite very significant price spikes of meat and cheese, i.e. by $20 \%$ in 2008 , which had a very small temporary impact of $0.5-2 \%$ on consumption. Increasing consumption of whey based dairy products and eggs (rich in protein) is rather recent. Probably the underlying

${ }^{1}$ In the empirical section of the paper, edible offals are included in the red meat category as they originate for the most part from the same animals (mainly pigs and cattle). The data reproduced in Table A1shows that consumption of edible offals is, in practice, very small. 
reason for gradually increasing consumption of livestock products is linked to a strong preference for protein rich foods, which are considered more healthy than cereals (rich in carbohydrates) and sugar. Hence climate friendly diet choices have not materialised at the aggregate level due to such trends and preferences. Nevertheless, recommendations to avoid red meat, especially beef, seem to stay among priority means of reducing GHG emissions.

What would happen if consumers would start following the advice of decreasing red meat consumption? Would such a change promote the realisation of GHG abatement targets (-13\% during 2005-2020; specified in VNK 2008) imposed for Finnish agriculture? Since Finnish agriculture and land use is largely dominated by livestock production activities and feed crops, one might expect that reducing red meat consumption would be one of the viable means of reaching this target. This is because only reducing livestock activities would deteriorate domestic food security and increase imports of livestock products. But if red meat demand decreased, decreasing domestic production would not mean weakening self-sufficiency of food. In general terms, agricultural policy system in Finland has been designed to maintain livestock production, with national subsidies coupled to production, in order to supply food for domestic demand. The balance between production and domestic demand, as well as the ability of the food sector to respond to changing demand, has been considered important. For this reason there are payments coupled to production to ensure sufficient production, and budgetary limits imposed for the national production coupled payments in order to avoid overproduction and trade distorting exports. Hence it is an important policy question how much GHG abatement can be achieved by reducing consumption of beef, pork, and lamb, which are most probably products whose reduced production would most effectively decrease GHG emissions. It has been already found that reduced tillage of organic soils (producing high levels $\mathrm{CO} 2$ emissions if tilled every year) could decrease agricultural GHGs even up to $10 \%$, theoretically, if implemented in all organic soils (Regina et. al. 2009). However, additional viable means of reaching this $13 \%$ reduction target are required.

Table 1. Meat, cheese and eggs consumption (mill. kg ) in Finland 1995-2011. Source: TIKE 2012, p. 171.

\begin{tabular}{|c|c|c|c|c|c|c|}
\hline & Beef & Pork & Poultry & $\begin{array}{l}\text { Total meat } \\
\text { cons. }\end{array}$ & Cheese & Eggs \\
\hline 1995 & 96 & 165 & 44 & 304 & 78 & 60 \\
\hline 2000 & 99 & 169 & 69 & 337 & 92 & 51 \\
\hline 2005 & 98 & 176 & 84 & 358 & 98 & 49 \\
\hline 2010 & 99 & 189 & 98 & 386 & 115 & 53 \\
\hline 2011 & 99 & 196 & 99 & 394 & 121 & 54 \\
\hline $\begin{array}{l}\text { Change } \\
\text { 1995-2011 (\%) }\end{array}$ & 3,0 & 19 & 122 & 30 & 55 & -10 \\
\hline $\begin{array}{l}\text { Change } \\
\text { 2005-2011 (\%) }\end{array}$ & 1 & 11 & 18 & 10 & 23 & 10 \\
\hline
\end{tabular}

While it is certainly true that, ceteris parebus, a reduction in meat consumption and production would reduce GHG emissions, more analysis of the issue is required for several reasons: first, compensatory behaviour in consumption is likely to take place with meat consumption being replaced by consumption of other foods; second, the determinants of agricultural supply are complex due to the distortions of incentives introduced by agricultural policies as well as output jointness in production (for instance, appr. $85 \%$ of domestic beef production in Finland is a side-product of milk production); and third, in a globalised world, reductions in domestic consumption do not translate automatically to lower domestic production.

Reduction of meat consumption as a GHG-reducing strategy is an option that we analyse in this paper by combining a diet model and a sector-level model of agricultural production. Effects on livestock production, crop production and foreign trade were estimated using MTT's Dremfia sector model. The model is based on microeconomic theory of competitive markets.

In the literature similar kind of analyses on relatively large counter-factual demand changes coupled to economic agricultural sector modelling are rare. Audsley et. al. (2010) evaluated the consequences of large food demand changes (as big as meat demand -50\%) on land use and GHG emissions in the UK using life cycle analysis and expert assessment on the overall demand change scenarios. However Audsley et. al. (2010) did not simulate implied changes in overall food diets, agricultural production and land use based on economic and market behaviour, but attempted to evaluate the feasibility of such drastic demand changes in the UK context. 
The paper is organised as follows. First we evaluate how reduced demand for red meat affects demand for other foodstuffs, especially the close substitutes of red meat. Then we evaluate how the reduced red meat demand and related dietary changes, if they were already realised in 2013, would influence agricultural production in Finland, as well as meat imports and exports. In this we utilise MTT's Dremfia sector model, which also includes a detailed description of agricultural policies and especially production-linked national subsidies that are designed to maintain agricultural production and livestock sector. Lastly we make concluding remarks on the meaning of the results for the ongoing policy debate on climate policies and sustainable agriculture.

\section{Response of the Finnish diet to a reduction in red meat consumption}

If people ate less meat, they would probably increase their consumption of substitutes and reduce that of complements, which means that the overall impact on the diet is not straightforward. The objective of this first part of the analysis is therefore to simulate how the entire Finnish diet would respond to a $20 \%$ decrease in red meat consumption, which implies an increase in the consumption of other foodstuffs, and most likely of those with relatively high protein content.

\section{Diet models}

Mathematical programming is used in order to simulate the dietary changes that would take place if meat consumption were to be reduced in Finland. The basic idea underlying the model is that, given the persistence of dietary patterns and preferences, it is reasonable to assume that consumers, when reducing meat consumption, would seek to replace the foregone energy through substitutions that would modify their current diet as little as possible. This paradigm has been used previously to simulate the impact of cost constraints on nutrient density (Darmon et al. 2002) and to analyse how various dietary norms, if implemented, would affect food consumption in various countries or sub-population groups (Srinivasan et al. 2006, Shankar et al. 2008, Arnoult et al. 2010).

The objective function of our quadratic programming model measures the distance between the existing diet $x$ and the reduced-meat diet $x^{\prime}$, which can be formally expressed as:

$$
\operatorname{Min}_{x_{i}} \sum_{i \in F} \alpha_{i}\left(\frac{x_{i}^{\prime}-x_{i}}{x_{i}}\right)^{2}, \text { where } \alpha_{i}=\frac{e_{i} x_{i}}{\sum_{i \in F} e_{i} x_{i}}
$$

The distance measure in (1) is the weighted sum of squared deviations between the two diets $x$ and $x^{\prime}$. Deviations are expressed in percentage terms to prevent an unnatural situation where items that are consumed in relatively small amounts at the baseline increase or decrease greatly in percentage terms when the diet is reformulated. The weights $\alpha_{i}$ are the contributions of the food products to the original total energy intake, which are easily computed from the calorific coefficients $e_{i}$ for each food item. The objective function is minimised over the whole set $F$ of food items originally consumed in Finland.

The new diet must satisfy the additional constraint that meat consumption is reduced by $20 \%$ as compared to the existing diet:

$$
\sum_{i \in M} x_{i}^{\prime} \leq 0.8 * \sum_{i \in M} x_{i}
$$

where the set $M$ denotes all the goods (i.e. meats) that are targeted by the reduction. Given past successes of public health initiatives in Finland to modify diets (Prättälä 2003), this 20 percent reduction seems achievable through measures aimed at improving informed choices (e.g., educational programs, informational campaigns, labelling). We also impose constancy of total energy intake through the following equation:

$$
\sum_{i \in F} e_{i} x_{i}^{\prime}=\sum_{i \in F} e_{i} x_{i}
$$

This constraint forces the model to find foods so as to compensate for the reduction in energy intake brought about by the reduction in meat consumption. It therefore captures the homeostatic mechanisms of appetite and energy regulation summarised by Taubes (2001) as follows: "Despite all expectations to the contrary, people tend 
to consume the same number of calories despite whatever diet they try." Further, imposing constancy of food energy allows us to interpret the results of the simulations as diet composition effects, as we believe that reduction of food wastes, while desirable, is best analysed as a separate issue.

Finally, because it seems intuitive that meat would be replaced by other protein-rich foods, and that, as discussed in the introduction, recent evolution of Finnish food consumption confirms that intuition, constancy of protein intake is also imposed in one of the two scenarios:

$$
\sum_{i \in F} p_{i} x_{i}^{\prime}=\sum_{i \in F} p_{i} x_{i}
$$

where $p_{i}$ is the conversion factor of food item $i$ into proteins.

\section{Data}

Average Finnish food consumption is quantified on the basis of food availability data for the year 2008 and 58 food commodities (Tike 2010, p. 8-9). This type of data measures food available for consumption by difference in a food balance sheet and its advantages and limitations are discussed in Srinivasan et al. (2006). The 58 food commodities are grouped into 11 aggregates, as described in Table A1 in the Appendix.

\section{Results}

Table 2 gives the simulation results in terms of the broad commodity categories that Tike (2010) uses in food availability data. In addition, the 'meat' category has been broken down into a subgroup comprising the meats targeted for reduction in consumption (namely beef, pork, lamb and edible offals and a subgroup comprising other meats (mainly poultry). First focusing on Model 1, which imposes constancy of protein intake, the results indicate that reduction in the consumption of red meat would be partially offset by an increase $(+11 \%)$ in the consumption of other meat and animal products (eggs: $+6 \%$, fish: $+11 \%$, milk: $+5 \%$ ) that represent intuitively natural substitutes for meat. The impact on the consumption of plant-based foods would be much more limited (cereals: $+2 \%$, vegetables: $+3 \%$ ), with the model even predicting a marginal decrease in sugar consumption.

Table 2 also reports the results of simulations that did not impose the protein constraint (4). In that case (referred to as Model 2 in Table 2) the pattern of adjustment is uniform across all food commodities, with the percentage changes varying only from $1.9 \%$ for the pulses group to $2.6 \%$ for the vegetables group. This model seems to be incapable of capturing the natural relationships of substitutability that exist between meat and other goods.

Table 2. Simulated changes in the consumption of food products, if red meat consumption is reduced by $20 \%$. Two cases: Model 1 in which the amount of protein food remains constant, and Model 2 where it may decrease.

\begin{tabular}{|c|c|c|c|c|c|}
\hline \multirow[b]{3}{*}{ Food category } & \multirow{3}{*}{$\begin{array}{l}\text { Protein constraint } \\
\text { Original diet, } \mathrm{g} \mathrm{day}^{-1} \text { capita }^{-1}\end{array}$} & \multicolumn{2}{|c|}{ Model 1} & \multicolumn{2}{|c|}{ Model 2} \\
\hline & & \multicolumn{2}{|c|}{ Yes } & \multicolumn{2}{|c|}{ No } \\
\hline & & $\begin{array}{l}\text { Optimised diet } \\
\text { g day }^{-1} \text { capita }^{-1}\end{array}$ & Change \% & $\begin{array}{l}\text { Optimised diet } \\
\text { g day }^{-1} \text { capita }^{-1}\end{array}$ & Change \% \\
\hline Cereals & 220 & 225 & $2.2 \%$ & 224 & $2.1 \%$ \\
\hline Potatoes & 164 & 166 & $1.6 \%$ & 167 & $2.2 \%$ \\
\hline Sugar & 94 & 94 & $-0.4 \%$ & 96 & $2.3 \%$ \\
\hline Pulses, nuts, cocoa & 11 & 12 & $2.4 \%$ & 12 & $1.9 \%$ \\
\hline Vegetables & 188 & 193 & $2.7 \%$ & 193 & $2.6 \%$ \\
\hline Fruits and berries & 223 & 224 & $0.6 \%$ & 228 & $2.5 \%$ \\
\hline Meat (all) & 207 & 182 & $-11.9 \%$ & 177 & $-14.0 \%$ \\
\hline Meat (red) & 152 & 121 & $-20.0 \%$ & 121 & $-20.0 \%$ \\
\hline Meat (other) & 55 & 61 & $10.6 \%$ & 56 & $2.4 \%$ \\
\hline Eggs & 26 & 27 & $6.1 \%$ & 26 & $2.3 \%$ \\
\hline Fish & 43 & 47 & $10.6 \%$ & 44 & $2.0 \%$ \\
\hline Milk products & 597 & 627 & $5.0 \%$ & 609 & $2.2 \%$ \\
\hline Oils and fat & 41 & 40 & $-0.4 \%$ & 42 & $2.3 \%$ \\
\hline
\end{tabular}




\section{Impacts of the changed food diet on agricultural production}

Next we evaluate how the simulated changes in diet presented above, if they were already realised in 2013, would influence agricultural production and the greenhouse gas emissions of the agricultural sector in Finland. We use MTT's Dremfia agricultural sector model, which includes not only domestic production but also imports and exports of the most important agricultural products as endogenous variables. However, demand for foodstuffs is exogenous in the model since each agricultural product is given demand trends based on the observed trends in 1995-2010 (demand trends are considered to remain unchanged after 2011) while domestic consumption is allowed to change by only 1-2\% from the given trend value (largely for technical and computational reasons, to avoid unfeasible solutions). Hence the simulated food demand changes resulting from a $20 \%$ reduction in red meat demand can be studied consistently with the model, which provides economically rational reactions in imports, exports and domestic production following the demand changes.

\section{The sector model}

Dremfia is a dynamic recursive model for simulating agricultural production and markets from 1995 up to 2020 (Lehtonen 2001, 2004). The underlying hypothesis in the model is that in competitive markets, producers engage in profit maximising behaviour and consumers engage in utility maximising behaviour. According to microeconomic theory, this leads to welfare maximising behaviour in the agricultural sector. Decreasing marginal utility of consumers and increasing marginal cost per unit produced in terms of quantity lead to equilibrium market prices that are equal to the marginal cost of production in competitive markets. Each region specialises in products and production lines that yield the greatest relative profitability, taking into account the profitability of production in other regions and consumer demand. This means that total use of different production resources, including farmland, in different regions is optimised in order to maximise sectoral welfare, taking into account differences in resource quality, technology, costs of production inputs and transportation costs (spatial price equilibrium; Takayama and Judge 1971).

Sector models of agriculture simulating competitive markets under fixed resources and production technology have long been common tools in agricultural economics (McCarl and Spreen 1980). Farmland resources are typically assumed to be fixed, while quasi-fixed inputs, such as buildings and machinery, typically have a lifespan of 10-30 years.

The Dremfia model consists of two main parts: (1) a technology diffusion model that determines sector-level investments in different production technologies; (2) an optimisation routine simulating annual production decisions (within the limits of fixed factors) and price changes, i.e. supply and demand reactions, by maximising producer and consumer surplus subject to regional product balance and resource (land and capital) constraints (Fig. 1).

Production activities include a number of different animals, hectares under different crops and set-aside, feed diet composition, chemical and manure fertiliser use and the resulting crop yield level. Products and intermediate products may be transported between the regions at certain transportation costs. In a dynamic recursive model, parts (1) and (2) interact each year so that prices from the market-simulating optimisation model enter the technology diffusion model, representing sector-level investments in each region, and changes in animal production capacities of different techniques enter the market model in the following year.

Technical change and investments, which imply evolution of farm size distribution and production capital in different regions, are modelled as a process of technology diffusion, as described by Soete and Turner (1984).

The endogenous evolution of farm size structure and technology is important in simulating regional shifts in production due to policy or demand changes, influencing the capacity of different regions to increase or decrease production.

The investment model and resulting production capacity changes are, however, closely linked to the market model determining production (including land use, fertilisation, feeding of animals and yield of dairy cows, for example), consumption and domestic prices. Our market model is a typical spatial price equilibrium model (see, e.g. Cox and Chavas 2001), except that no explicit supply functions are specified, i.e. supply is a primal specification. 


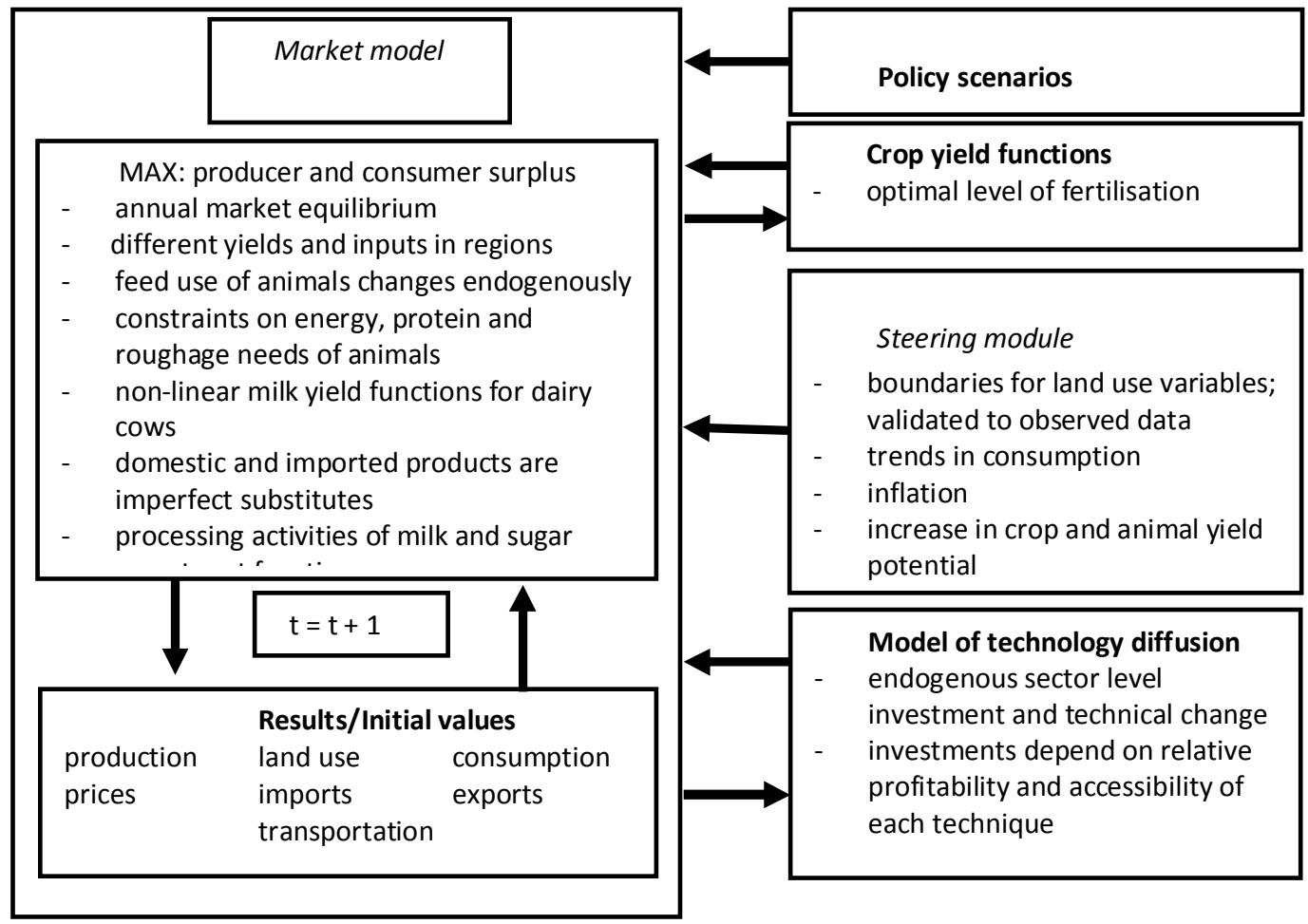

Fig. 1. Basic structure of the Dremfia model

Foreign trade activities are included in Dremfia. The Armington assumption (Armington 1969) is used. Imported and domestic products are imperfect substitutes, i.e. endogenous prices of domestic and imported products are dependent. This means that the demand functions of domestic and imported products are coupled through substitution elasticities. Exogenously given EU prices influence domestic prices, but domestic prices may be different from EU prices, depending on the balance between supply and demand in domestic markets. For example, decreasing domestic supply may drive up domestic prices slightly even if EU prices were stable, because consumers do not see imported products, especially beef and many dairy products, as perfect substitutes to domestic ones.

Four main areas are included in the model: Southern Finland, Central Finland, Ostrobothnia (the western part of Finland) and Northern Finland. Production in these areas is further divided into sub-regions on the basis of the support areas. In total, there are 17 different production regions. This allows a regionally disaggregated description of policy measures and production technology.

Use of variable inputs, such as fertilisers and feedstuffs, is dependent on agricultural product prices and fertiliser prices through production functions. The nutrients from animal manure are explicitly taken into account in the economic model. Feeding of animals may change in the short term within certain bounds imposed by fixed production factors and animal biology, provided that nutrition requirements, such as energy, protein, phosphorous and roughage needs, are fulfilled. Specific production functions are used to model the dependency between the average milk yield of dairy cows and the amount of the grain-based feedstuffs used in feeding. The yield of dairy cows responds to changes in the prices of milk and feedstuffs. The model includes 18 different processed milk products and their regional processing activities.

The overall Dremfia model replicates ex post production in 1995-2011 very closely. The model is built to reach a steady-state equilibrium, long- and medium-term changes in aggregate amounts and regional location, in a 10-15 year period given no further policy changes. There is a gradual adjustment built into the model, as fixed production factors and animal biology make immediate adjustments costly. Non-linear production functions, estimated using statistical methods, are concave, i.e. the marginal productivity decreases with output. The steady-state equilibria found at the whole country level are also due to limited domestic consumption of foodstuffs and the costs of exports. For example, the transportation costs of cereals from and to Finland are relatively high compared to cereal prices, especially when the EU price level is low (such as in 2009). Another reason for steady states in the 10-15 year period is the Armington assumption, i.e. the imperfect substitution between domestic and imported products. A more detailed presentation of the model can be found in Lehtonen $(2001,2004)$. 
A simple greenhouse gas calculator has been created in the Dremfia sector model. The GHG calculation largely follows the principles and parameters of the national greenhouse gas inventory practices (Statistics Finland 2012). However, the calculation does not include lambs, reindeers, horses or fur animals. Also, certain nitrogen fluxes are not specified in full detail, such as crop residues and burned crop residues. Despite these deficiencies the GHG calculator in Dremfia calculates more than $90 \%$ of the $\mathrm{CO}$-equivalent agricultural GHG emissions reported in Finland. The increasing trend in the milk yield of dairy cows and the implied increase in $\mathrm{N}$ excretion are accounted for, and hence GHG emissions per cow are valid and checked against the national inventory reports.

\section{Sector model results}

The demand changes summarised in Table 2 were included in the Dremfia sector model from the year 2013 onwards. Let us refer to the demand scenarios in Table 2 as meatm 1 (reduced red meat demand assuming protein intake unchanged in the food diet) and meatm2 (reduced red meat demand allowing protein intake to change in the food diet). According to the diet model results, the decreasing demand for red meat consumption is largely compensated by increasing demand for other livestock products, including poultry meat (2-11\%), milk products $(2-5 \%)$ and eggs (2-6\%). Also fish, cereals, vegetables, fruits, sugar and oil demand would increase by a few percent. This, however, has little effect on land use in the model, which excludes fish, vegetables and fruits.

In agriculture, these changes in demand will lead to an increase in production of poultry and a small growth in the number of dairy cows. Overall beef production (Fig. 2) would not drop by more than $5 \%$ because, even though the number of suckler cows would be reduced, the number of dairy cows would simultaneously increase. Beef imports account for a significant and growing share of consumption in the baseline, reaching 25\% market share in 2012. $85 \%$ of domestically produced beef comes from dairy cattle, which is on the increase in the meatm 1 and meatm 2 scenarios. Due to the inelastic supply of domestic beef, the $20 \%$ drop in the overall demand for beef would result in a relatively modest reduction in consumption of domestic beef (Fig.3) while imports of beef would be decreased by as much as $50 \%$ (Fig. 4).. In absolute terms, the demand of domestic beef decreases by 7-8 million kg and the demand of imported beef by 13 million $\mathrm{kg}$ in both meatm 1 and meatm 2 scenarios. Due to this imperfect substitution between domestic and imported beef, beef exports increase from low levels of 2 million kg per year up to 8 million $\mathrm{kg}$ per year in meatm 1 and meatm 2 scenarios as a result of decreased domestic demand and stable domestic beef production. Hence domestic beef would replace only a fraction of the decreased beef imports, due to reduced demand and imperfect substitution between domestic and imported beef. This imperfect substitution, verified by publicly available market data, is built in the Dremfia sector model through demand system parameters (e.g. substitution elasticity values; see Lehtonen 2001 for details)

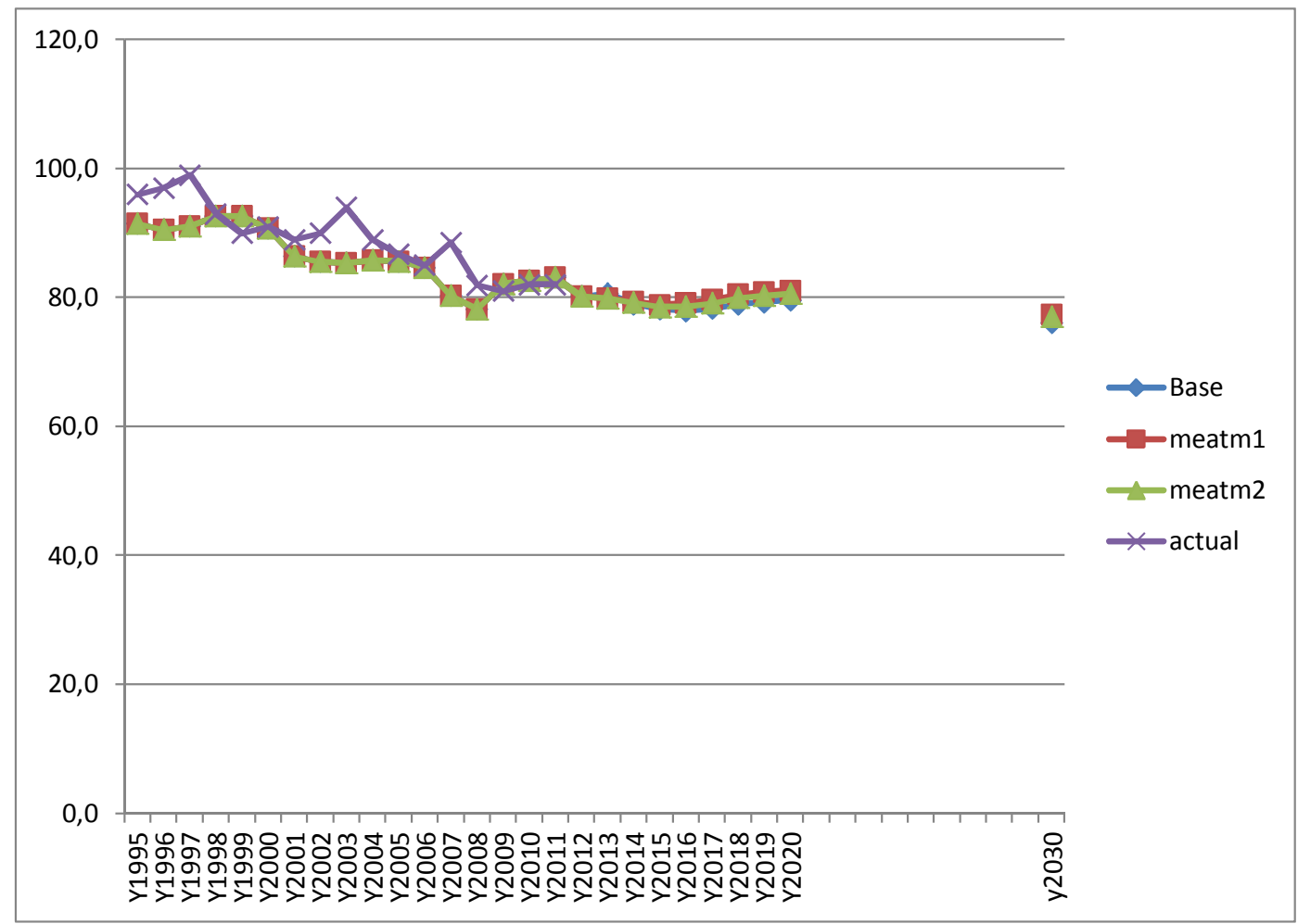

Fig. 2. Beef production (million $\mathrm{kg}$ ) in Finland in baseline, meatm 1 and meatm 2 scenarios. 


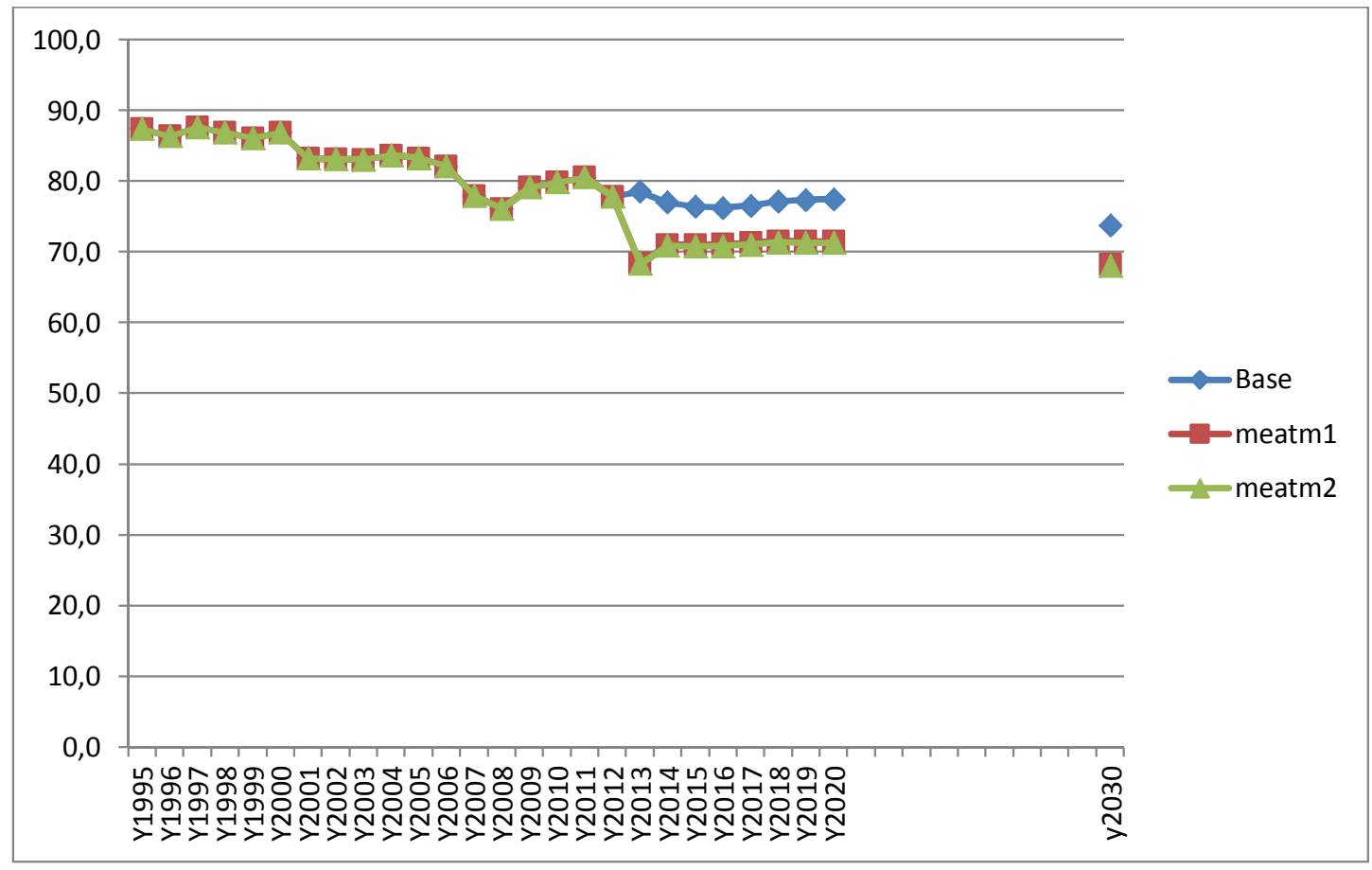

Fig. 3. Consumption of domestic beef (million $\mathrm{kg}$ ) in Finland in baseline, meatm1 and meatm2 scenarios

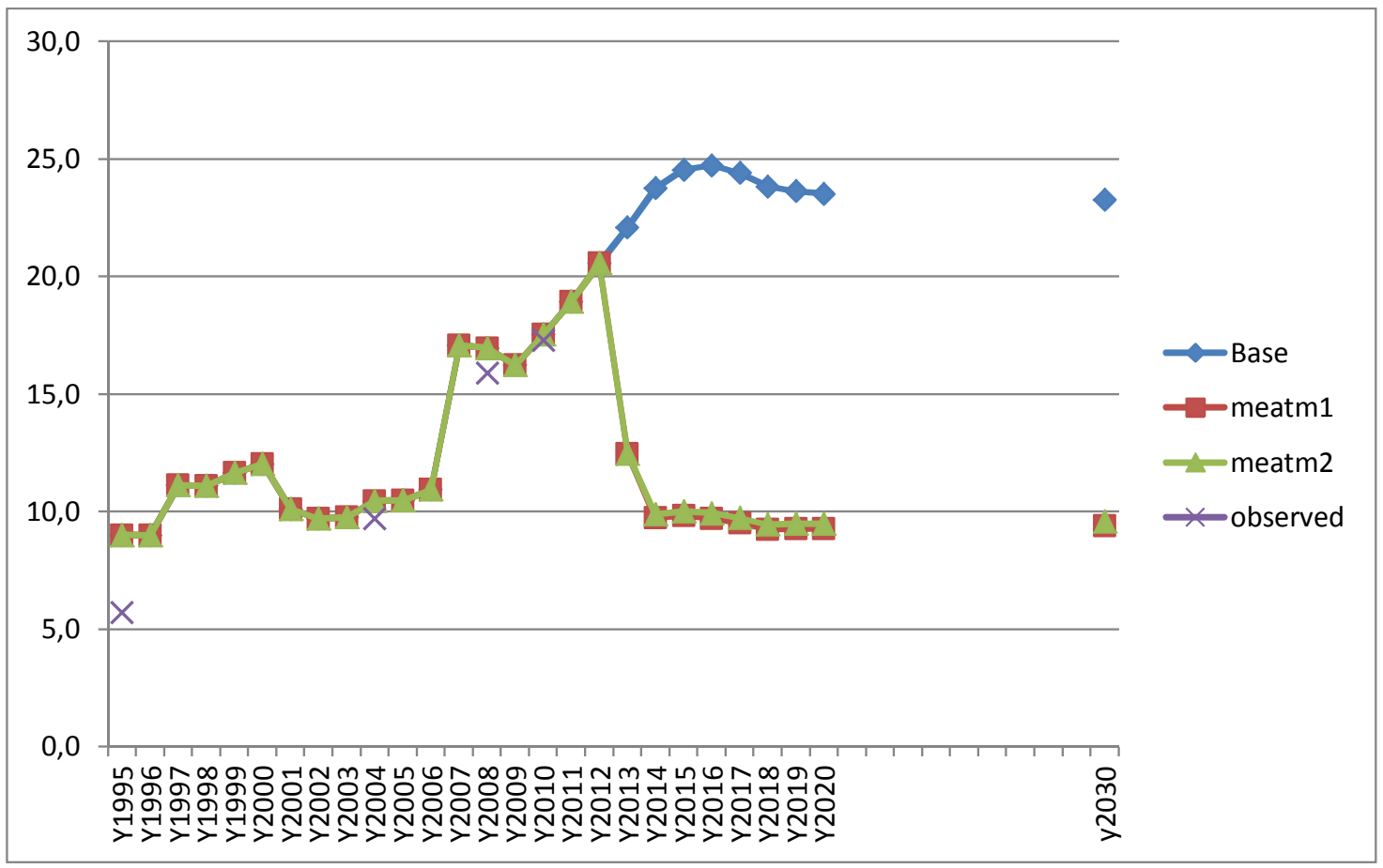

Fig. 4. Consumption of imported beef (million $\mathrm{kg}$ ) in Finland in baseline, meatm1 and meatm2 scenarios.

Suckler cow production is already a subsidy-driven production line in Finnish agriculture due to EU and national payments per head of animal, and beef prices are low compared to the variable costs of production. This explains the lack of responsiveness of the sector to changing market conditions: our results show that the dramatic decrease in beef demand in the meatm 1 and meatm 2 scenarios has surprisingly little impact on the increasing development of suckler cows. However, in scenario meatm1 the number of suckler cows ends up to level which is $10 \%$ lower than in the baseline (Fig 5). In scenario meatm2 the number of suckler cows reaches a level which is only $2 \%$ below the number of animals in the baseline. 


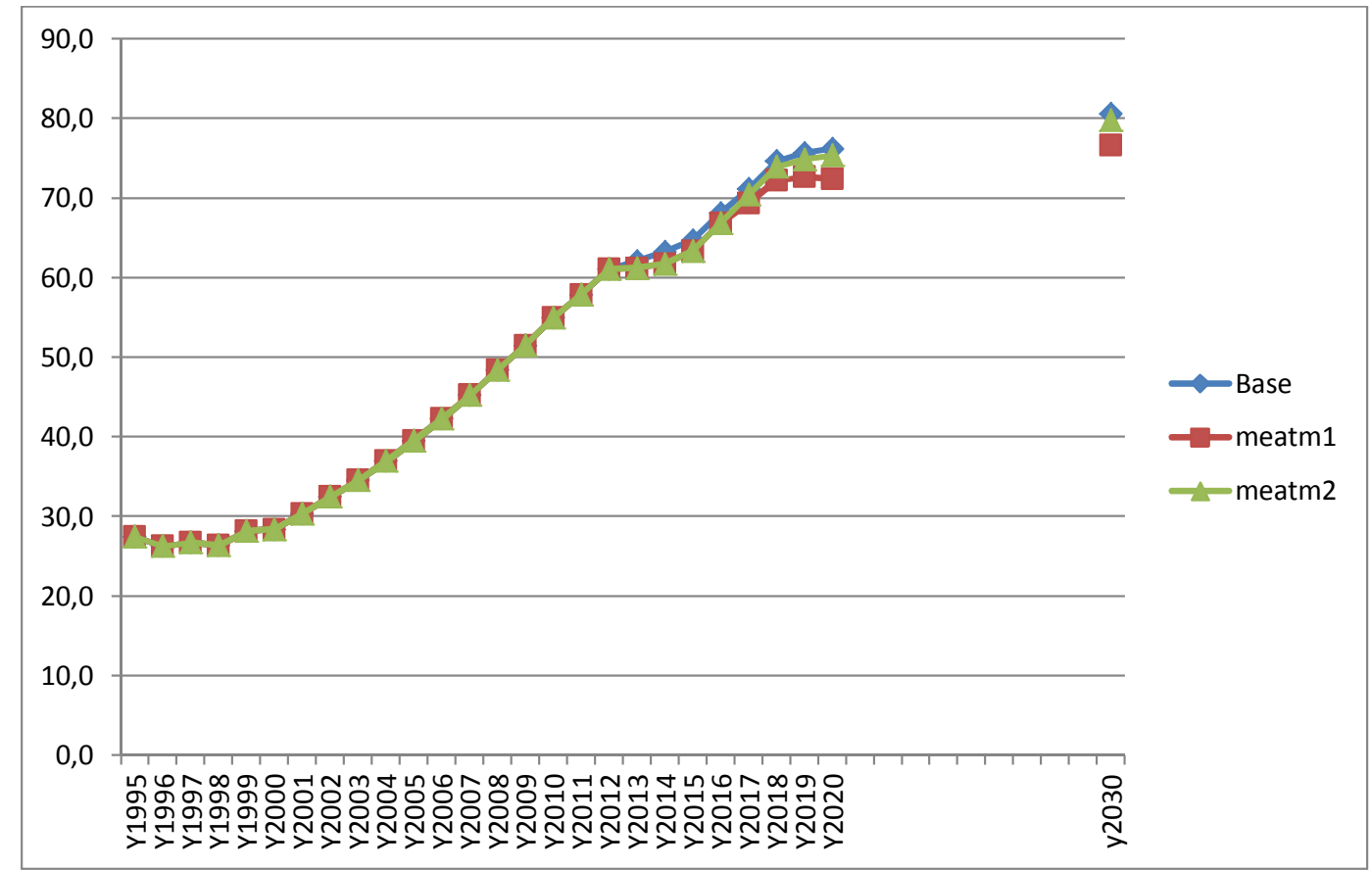

Fig. 5. Number of suckler cows (1000 heads) in Finland in baseline, meatm1 and meatm2 scenarios.

The same kind of imperfect substitution, as already seen between domestic and imported beef, drive the results in pigmeat sector. Production of pigmeat decreases by $15 \%$ in meatm 1 and meatm 2 scenarios, compared to the baseline (Fig.6). Pigmeat imports also see a relatively greater decrease than domestic production in the meatm1 and meatm 2 scenarios: When pork demand falls by $20 \%$, domestic demand for domestic pigmeat decreases relatively more than the demand for imported pigmeat (Figures 7,8). Consequently, the number of pigs decreases by $15 \%$, and pork imports by even more than $50 \%$. This is due to the expected decrease in domestic pork prices, which affect import volumes relatively more and faster than domestic production.

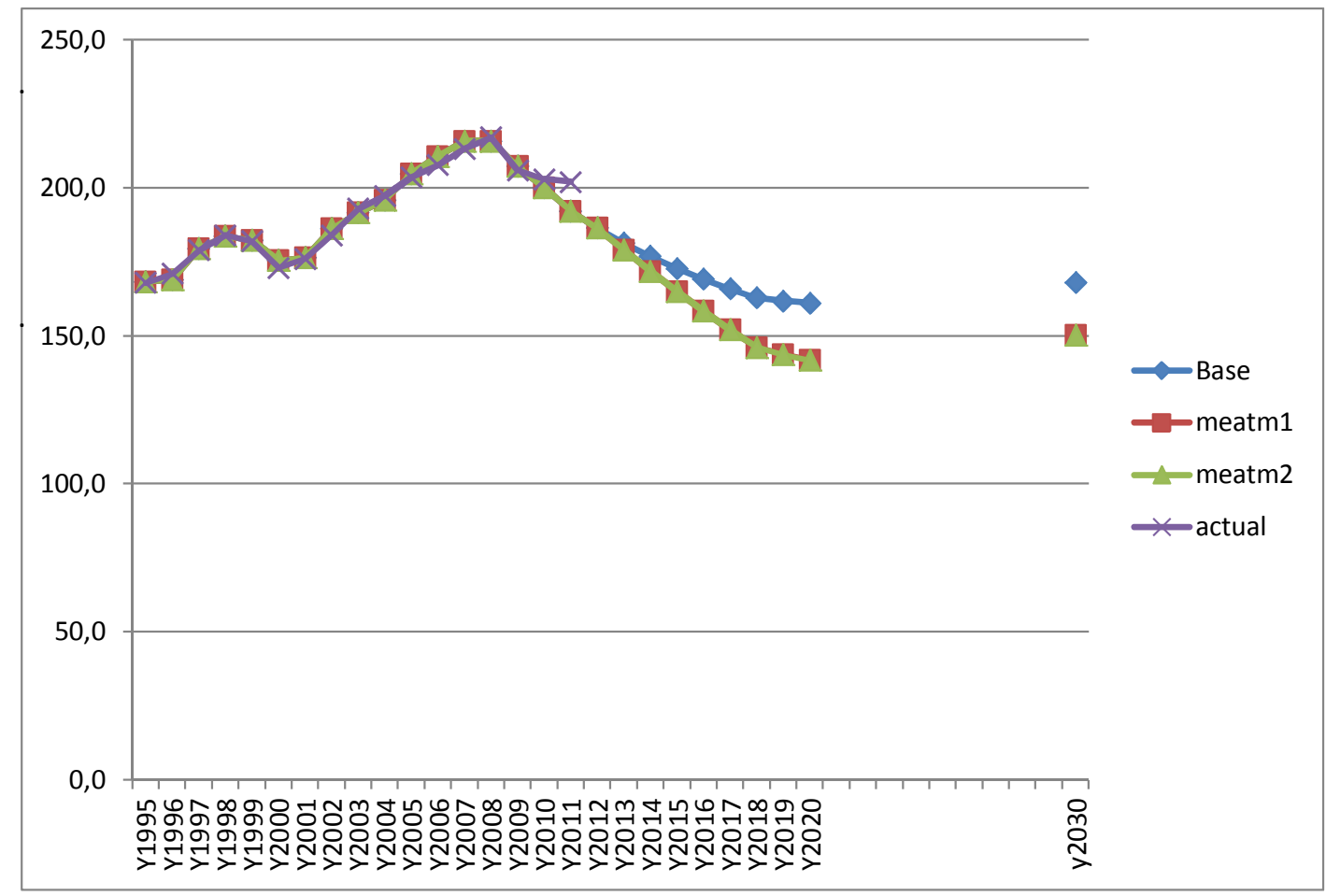

Fig. 6. Pigmeat production (million $\mathrm{kg}$ ) in Finland in baseline, meatm1 and meatm2 scenarios. 


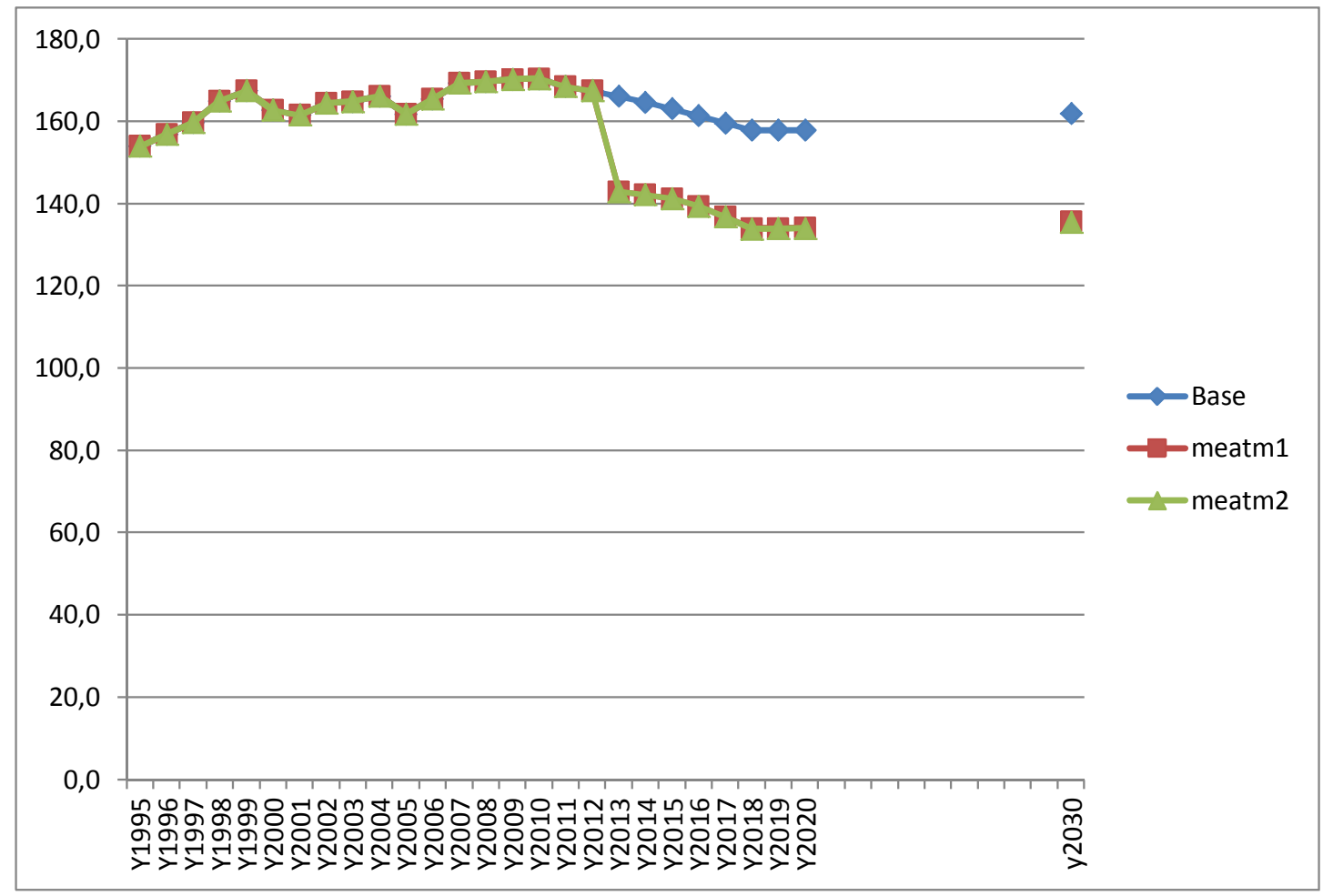

Fig. 7. Consumption of domestic pigmeat (million $\mathrm{kg}$ ) in Finland in baseline, meatm1 and meatm2 scenarios.

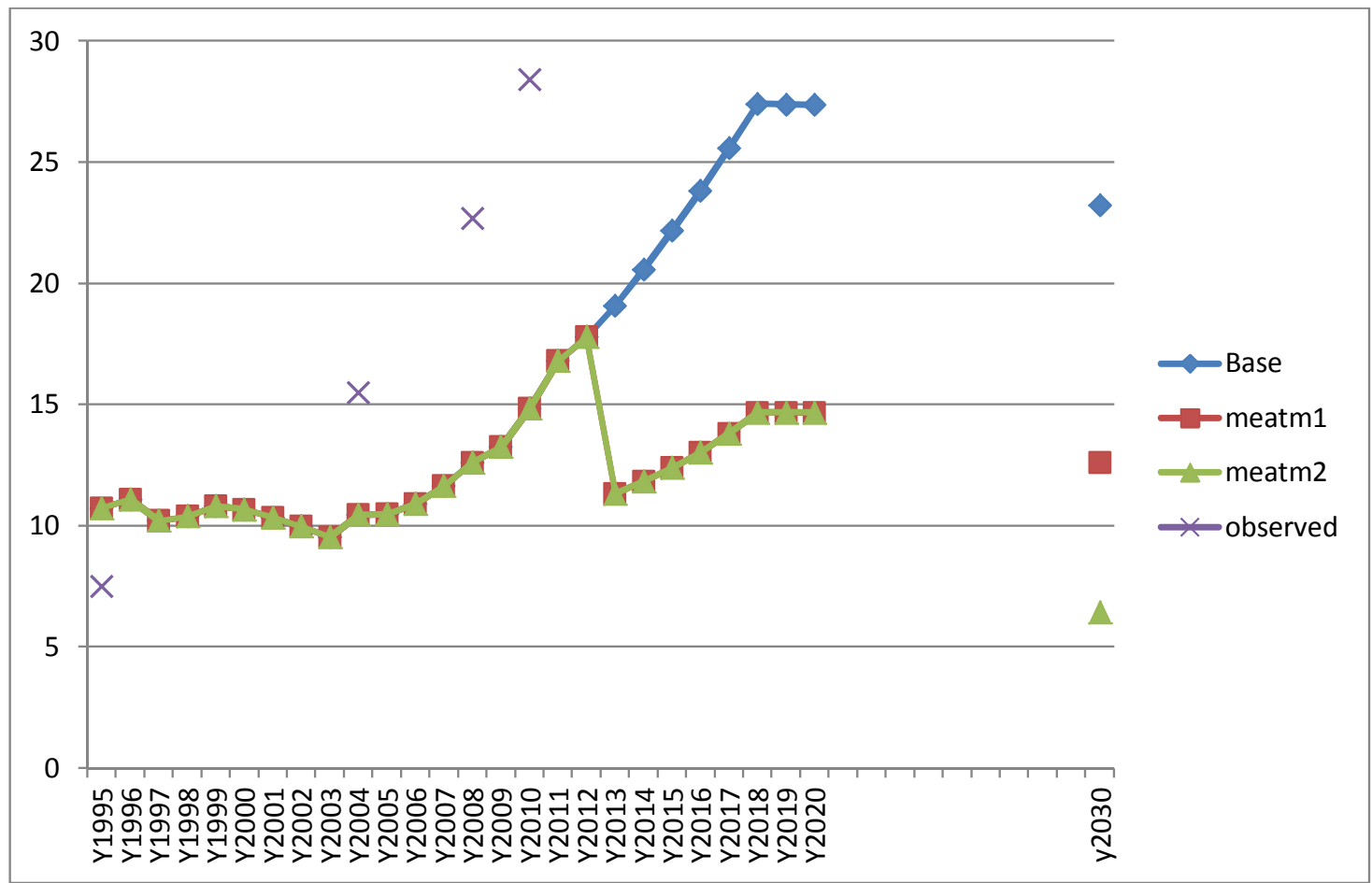

Fig. 8. Consumption of imported pigmeat (million kg) in Finland in baseline, meatm1 and meatm2 scenarios.

Pigmeat production is already driven down in the baseline by the unfavourable pigmeat prices assumed in OECDFAO (2012), which is utilised as a source of exogenous EU prices. The reduction in pigmeat production is also due to decoupled and decreased $(-55 \%)$ national payments for pigs and poultry animals, which were previously paid per head. Such supports comprised nearly 15\% of the annual turnover of a typical pig farm in Finland in 2008. However, a $20 \%$ decrease in pigmeat consumption would decrease domestic pigmeat production even further in the meatm 1 and meatm 2 scenarios, by $15 \%$ compared to the baseline (Fig. 7). 
Imports of pigmeat, driven by domestic prices of pigmeat, are the main substitute for domestic pigmeat. Since the $20 \%$ demand reduction in 2013 results in a significant decrease in pigmeat prices, pigmeat imports collapse immediately to a level of 11 million kg per year, which is approximately $40 \%$ less than pigmeat imports in the baseline (Fig. 8). Pigmeat exports would first increase after a demand shock of $-20 \%$, but after decreased production pigmeat exports cease almost completely in both the meatm 1 and meatm 2 scenarios. On the other hand, increasing poultry meat demand in the meatm 1 and meatm 2 scenarios gives a major boost to domestic poultry meat production as well as imports. The magnitude of the relative increase in both demand scenarios meatm 1 and meatm 2 is $10 \%$ (Fig. 9).

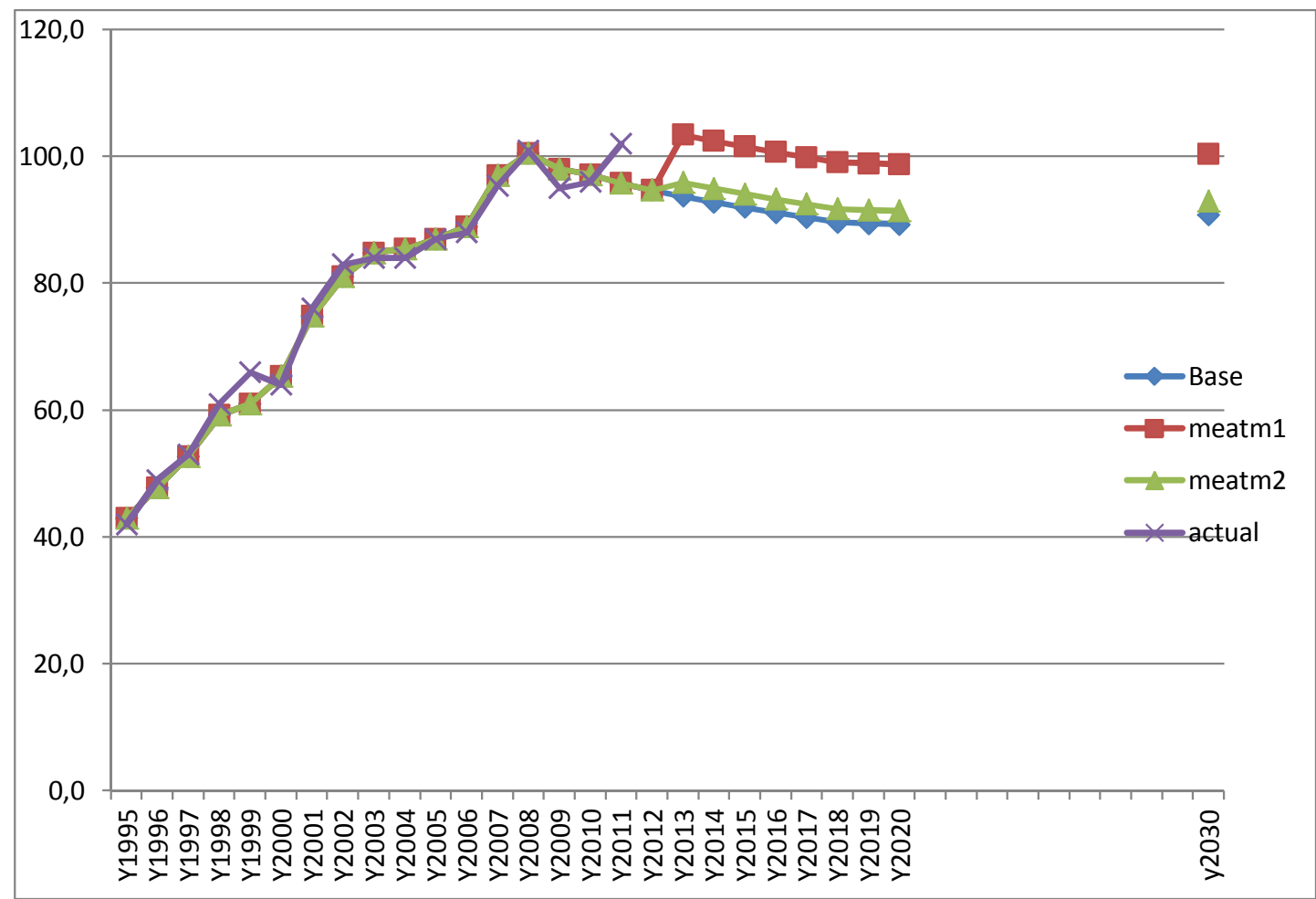

Fig. 9. Poultry meat production (million $\mathrm{kg}$ ) in Finland in baseline and in scenarios meatm1 and meatm2.

Overall, the impacts of the meatm 1 and meatm 2 scenarios on agricultural income are very small (only $+1-2 \%$ compared to the baseline), which is not surprising considering the increase in poultry meat production and slight increase in milk production, while pigmeat production suffers from the unfavourable evolution of the price ratio between pigmeat and cereal prices predicted by OECD-FAO 2012. Agricultural income would even increase slightly (between 1-2\%) in the meatm1 and meatm2 scenarios relative to the baseline, which is explained by the fact the substitution of poultry meat demand for pigmeat demand has a positive effect on the profitability of agriculture. This result is again impacted by the EU prices predicted by OECD-FAO 2012. The same EU prices were used in all scenarios, i.e. baseline, meatm 1 and meatm 2 .

Furthermore, the greenhouse gas (GHG) emissions of the agricultural sector (as defined in the national GHG inventory) would change hardly at all due to a $20 \%$ reduction in the demand for red meat. This is a direct implication of the increase in dairy, poultry meat and egg production, which together compensate for the decrease in GHG emissions due to a slight decline in beef production and an even significant fall in pork production. In fact, the simulated change in domestic GHG emissions due to reduced red meat production is even slightly positive $(+1 \%$; Fig. 10). This means that under current agricultural policy settings and market expectations even significant reductions in red meat demand would not directly lead to decreased GHG emissions in Finland. However, when accounting for very significant decreases in beef and pork imports, it is possible that the reduced red meat demand has the desired negative effect on global GHG emissions, ceteris paribus. However, such emissions reductions could not be calculated here since the beef and pork imports have a number of different origins, while the parameters used for the GHG emission calculations herein are the same as the ones used in the Finnish national inventory. 


\section{AGRICULTURAL AND FOOD SCIENCE}

H. Lehtonen \& X. Irz (2013) 22: 356-370

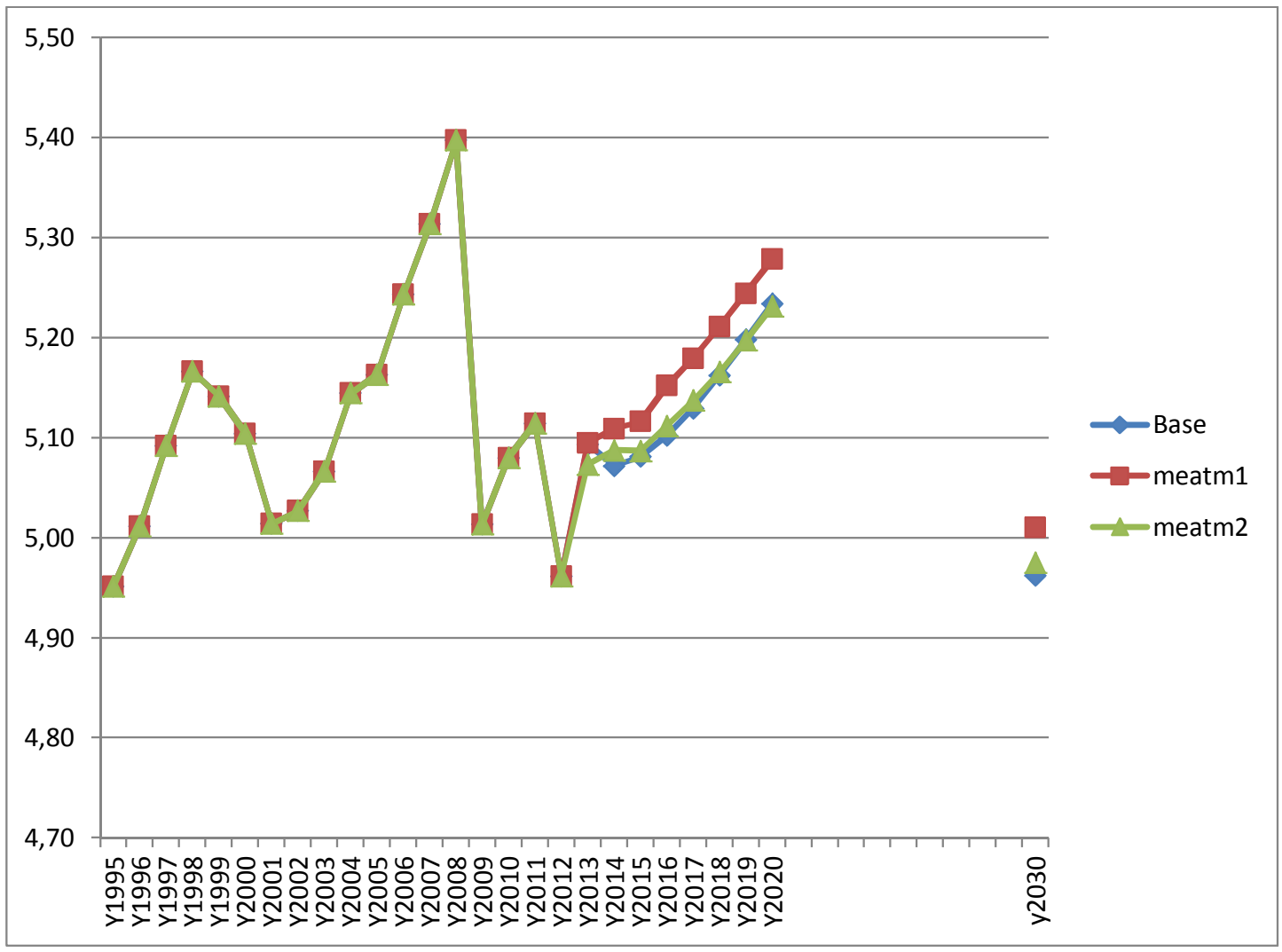

Fig. 10. Greenhouse gas emissions (Tg CO2 eq.) in Finland in baseline and in scenarios meatm1 and meatm2.

\section{Discussion}

In common with virtually all previous attempts at capturing the economy-wide effects of dietary change, our analysis also has some limitations linked to the way changes in food demand are simulated. The objective function (1), which makes intuitive sense and has been validated in other studies (Srinivasan et al. 2006, Shankar et al. 2008), is also somewhat ad-hoc and lacks flexibility to allow for varied relationships of substitution and complementarity among foods. There is a need for methodological improvements at that level by extending the consumer choice model to include linear constraints of the type considered in our article (namely, maximum combined amount of pork and beef consumed). However, our analysis makes sense at least when there is little change in overall food preferences. This seems to be valid currently since meat consumption has still been increasing in Finland in very recent years, despite greater discussion and awareness of the climate impacts of food and meat consumption in particular. Recent trends in food demand also show little overall changes, such as reductions in not only meat but also in dairy product consumption, considered necessary in terms of global GHG abatement by e.g. Garnett (2011). Assuming reductions in the consumption of all meat products as well as dairy products - which is relatively high in northern European countries for cultural and historical reasons (dairy used to ensure food security) - would already mean a major shift in northern European food diets as well as northern agriculture most likely, and pose major challenges for demand analysis as well. If demand of many products changes, the balance between supply and demand is also challenging to be simulated by agricultural sector models in which changes in production are subject to changes in marginal costs. Large demand changes imply large changes in production of many products as well, with possible shifts of regional resource use (land use - Audsley et al. 2010), implying marginal cost changes of many products. They may be significantly different from marginal costs based on most recent observations. In other words, economic models have limitations in analysing big systemic changes in the food economy.

Assuming large changes in food demand also become problematic if the change is assumed in one country only while assuming global demand and prices unaffected by similar demand changes. These may be the reasons why large changes in demand are rarely studied using consistent numerical economic models, validated and calibrated to observed empirical data (Audsley et. al. 2010). It has also not been attempted in this study which however opens up important issues and complexities in analysing effects of large unobserved (counterfactual) demand shifts related to ambitious GHG reduction targets. 


\section{Conclusions}

We analysed the likely impacts of a $20 \%$ reduction in red meat demand on Finnish agricultural production, assuming stable consumer preferences, expected agricultural product markets and no change in agricultural policies. Assuming minimal deviation from observed consumption patterns, we find that reduced red meat consumption would imply increased consumption of poultry meat, eggs, dairy products and fish, while there would be small increases in consumption of fruits and vegetables, peas and nuts, cereal products and sweets. By including the derived demand changes in an agricultural sector model, we show that livestock production in Finland, incentivised by national production-linked payments for milk and bovine animals, would decrease much less than $20 \%$ as a consequence of reduced red meat demand. In fact, there would be no change in the greenhouse gas emissions produced by Finnish agriculture. However, a $20 \%$ reduction in red meat consumption would be likely to have a relatively large impact on beef imports, while domestic beef production would remain stable due to a slight increase in milk production. Pigmeat production would decrease by approximately $15 \%$, which is an expected outcome of reduced demand, while poultry meat and egg production would expand in order to satisfy the increasing demand. Overall, reducing red meat consumption by as much as $20 \%$ is not likely to lead to a substantial decrease in livestock production or land use at a large in Finland, or greenhouse gas emissions from Finnish agriculture. The results of our analysis contribute to the ongoing debate on possible means of greenhouse gas abatement in the context of recent observed trends in food demand that show growing consumption of meat and other livestock products.

Hence the results suggest that even very significant single measures aiming for greenhouse gas emission abatement, such as reducing red meat consumption by $20 \%$, may not produce desired outcomes in domestic greenhouse gas emissions if implemented in isolation without further changes in consumer preferences or agricultural policies, which are among the main driving forces of agricultural production. However we do not claim that the reduced red meat demand is a useless means of decreasing GHG emissions, since decreasing pigmeat imports, which according to our results would fall much more drastically than domestic production, implies that there would be a decline in GHG emissions from pigmeat production elsewhere in the world. Such GHG emission reductions are not accounted for in the contribution of Finnish agriculture to the GHG emission inventory. In any case, our results show that changes in domestic consumption do not directly lead to reductions in domestic GHG emissions, which means that reducing red meat demand is not going to promote meeting the $-13 \%$ reduction target in agricultural GHG emissions 2005-2020. There might also be domestic "carbon leakage", driven by national production-linked agricultural subsidies. Such subsidies are intended to maintain existing livestock production, but seem not to be the appropriate ones when shifting agricultural supply to other food products demanded. In fact the protein crops, for example, are supported by some small payments coupled to production, but a large scale shift from livestock products to plant based protein (such as pulses, peas and nuts) would require also shifts of subsidy money from livestock product to demanded crop products (due to high production costs in northern Europe), not accounted for in our analysis.

Our main conclusion is that the current agricultural policy set-up, as well as consumer behaviour, is not supporting the idea of climate friendly food economy. If considerable shifts towards such ideals are to be realised up to 2020 or 2030, reformulation of the policy set-up promoting the change in policy systems should be going on already, taking into account the slow adjustments in agriculture and food production. Such shifts in agricultural policy or changed orientation of northern European agriculture are not simple, since it is traditionally perceived that the comparative advantage of northern European agriculture lies in livestock production, not in crop production, due to natural conditions. However, based on the recent CAP reforms as well as national policy reforms any serious developments in agricultural policies towards climate friendly food economy seems unlikely to realise before 2020 . Based on the compromise agreement on EU agricultural policy, reached in June 25, 2013 (implying relatively small changes overall), and framing the national implementations of agricultural policy, the status quo in agricultural policy is most likely to continue up to 2020 .

\section{Acknowledgement}

Financial support from project "Greenhouse gas scenarios for agriculture, forestry and other land use", funded by the Ministry of Agriculture and Forestry, made this study possible. 


\section{References}

Armington, P. 1969. A Theory of Demand for Products Distinguished by Place of Production. IMF Staff Papers 16: 159-178.

Arnoult, M. H., Jones, P. J., Tranter, R. B., Tiffin, R., Traill, W. B. \& Tzanopoulos, J. (2010). Modelling the likely impact of healthy eating guidelines on agricultural production and land use in England and Wales. Land Use Policy 27: 1046-1055.

Audsley, E., Chatterton, J., Graves, A., Morris, J., Murphy-Bokern, D., Pearn, K., Sandars, D. \& Williams, A. 2010. Food, land and greenhouse gases. The effect of changes in UK food consumption on land requirements and greenhouse gas emissions. The Committee on Climate Change. 151 p. Available on the Internet: https://dspace.lib.cranfield.ac.uk/bitstream/1826/6496/1/CCC Food_land_and_GHG_Sep\%202011.pdf

Cox, T.L. \& Chavas, J.-P. 2001. An Interregional Analysis of Price Discrimination and Domestic Policy Reform in the U.S. Dairy Sector. American Journal of Agricultural Economics 83: 89-106.

Darmon, N., Ferguson, E. L. \& Briend, A. 2002. A cost constraint alone has adverse effects on food selection and nutrient density: an analysis of human diets by linear programming. The Journal of Nutrition 132: 3764-3771.

Garnett, T. 2008. Cooking up a storm. Food, greenhouse gas emissions and our changing climate. Food Climate Research Network. Centre for Environmental Strategy University of Surrey. September 2008. 156 p. Available on the Internet: http://www.fcrn.org. uk/sites/default/files/Cuas_web.pdf

Garnett, T. 2011. Where are the best opportunities for reducing greenhouse gas emissions in the food system (including the food chain)? Food Policy 36: S23-S32.

Lehtonen, H. 2001. Principles, structure and application of dynamic regional sector model of Finnish agriculture. Academic dissertation. Systems Analysis Laboratory, Helsinki University of Technology. Publications 98. Agrifood Research Finland, Economic Research (MTTL). Helsinki. 265 p. http://lib.tkk.fi/Diss/2001/isbn9512256894/

Lehtonen, H. 2004. Impacts of de-coupling agricultural support on dairy investments and milk production volume in Finland. Acta Agriculturae Scandinavica, Section C - Food Economics 1: 46-62.

McCarl, B. A. and Spreen, T.H. 1980. Price Endogenous Mathematical Programming As a Tool for Sector Analysis, Amer. J. Agr. Econ. (1980):88-102.

OECD-FAO 2012. Agricultural Outlook 2012. www.agri-outlook.org

Prättälä, R. 2003. Dietary changes in Finland- success stories and future challenges. Appetite 41(3): 245-249.

Regina, K., Lehtonen, H., Nousiainen, J. \& Esala, M. 2009. Modelled impacts of mitigation measures on greenhouse gas emissions from Finnish agriculture up to 2020. Agricultural and Food Science 18: 477-493.

Soete, L. \& Turner, R. 1984. Technology diffusion and the rate of technical change. The Economic Journal. 94: 612-623.

Srinivasan, C.S., Irz, X. \& Shankar B. 2006. An assessment of the potential consumption impacts of WHO dietary norms in OECD countries. Food Policy 31: 53-77.

Shankar, B., Srinivasan, C.S. \& Irz, X. 2008. World Health Organization dietary norms: A quantitative evaluation of potential consumption impacts in the United States, United Kingdom and France. Review of Agricultural Economics 30: 151-175.

Statistics Finland, 2012. Greenhouse gas emissions in Finland 1990-2010. National Inventory Report under the UNFCCC and the Kyoto Protocol. Available on the Internet: http:\|www.stat.filgreenhousegases

Takayama, T. \& Judge, G.G. 1971. Spatial and Temporal Price and Allocation Models. Amsterdam, North-Holland Publishing Company. $528 \mathrm{p}$

Taubes, G. 2001. The soft science of dietary fat. Science 291: 2536-2545.

VNK 2008. Pitkän aikavälin ilmasto- ja energiastrategia. Valtioneuvoston selonteko eduskunnalle 6. päivänä marraskuuta 2008. 160 p. (in Finnish). http://www.tem.fi/files/21079/TEMjul_36_2008_energia_ja_ilmasto.pdf

Tike 2010. Ravintotase 2008 ja 2009 (ennako). Maa- ja Metsätalousministeriön tietopalvelukeskus, Helsinki, Finland. Availabe on the Internet: http://www.maataloustilastot.fi/en/node/913

Tike 2012. Yearbook of farm statistics 2012. Maa- ja Metsätalousministeriön tietopalvelukeskus, Helsinki, Finland.

Vinnari, M. 2008. The future of meat consumption - Expert views from Finland. Technological Forecasting and Social Change 75: 893-904.

VNR 2005. Suomalaiset ravitsemussuositukset - ravinto ja liikunta tasapainoon 2005. 56 p. Available on the Internet: http://www. ravitsemusneuvottelukunta.fi/portal/fi/ravitsemussuositukset/suomalaiset+ravitsemussuositukset/ 
Appendix 1, Table A1: Food availability data used in the simulations

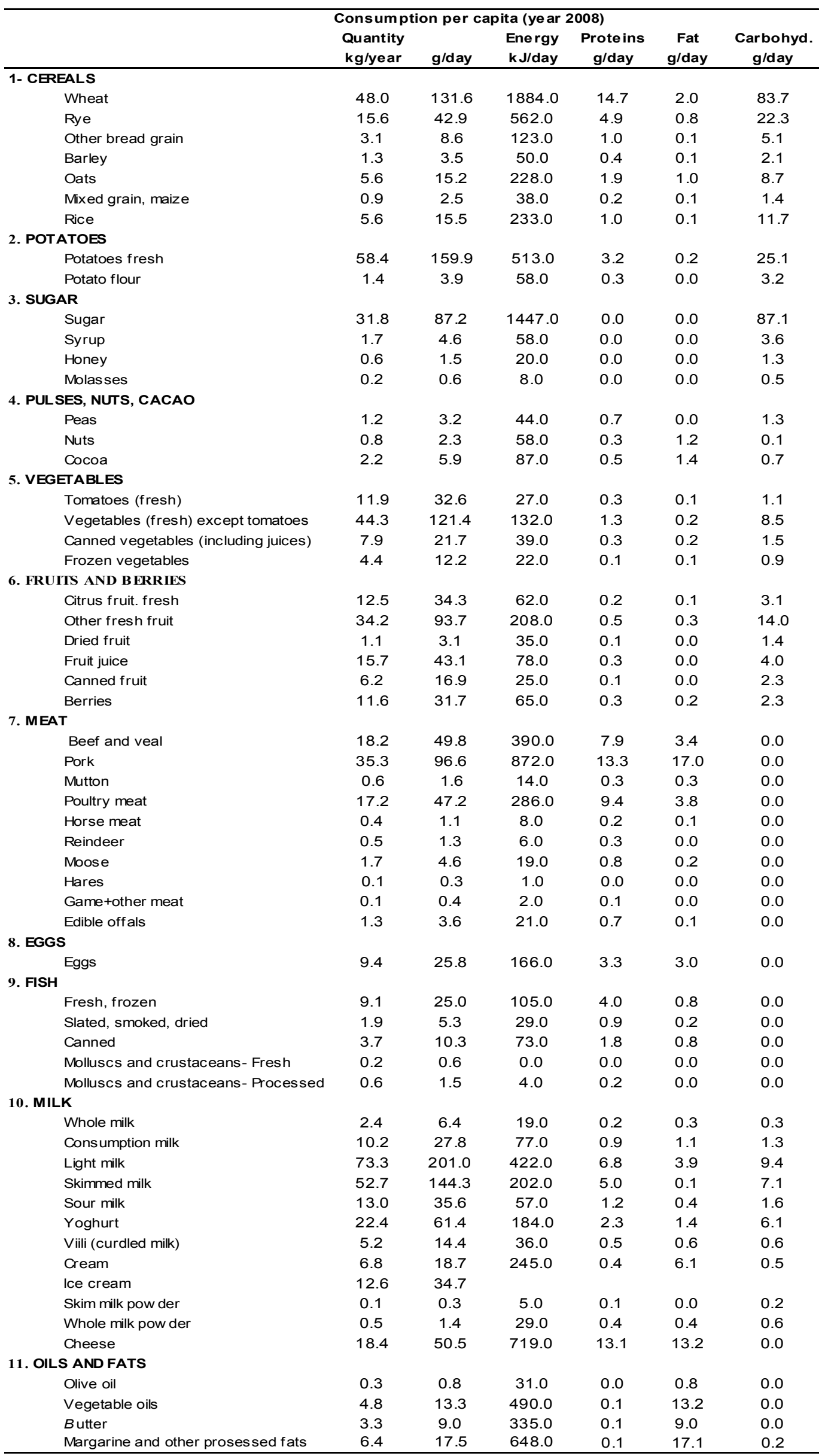

